\title{
Importance of cardiovascular disease risk management in patients with type 2 diabetes mellitus
}

This article was published in the following Dove Press journal: Diabetes, Metabolic Syndrome and Obesity:Targets and Therapy 23 May 2014

Number of times this article has been viewed

\section{Daniel Lorber}

Division of Endocrinology, New York Hospital Queens, Department of Medicine, Weill Medical College of Cornell University, New York, NY, USA
Correspondence: Daniel Lorber Division of Endocrinology, New York Hospital Queens, 5945 I6Ist Street, Flushing, New York, NY I I 365, USA $\mathrm{Tel}+17187623111$

Fax +1 7183536315

Email lorberdan@aol.com
Abstract: Type 2 diabetes mellitus (T2DM) is commonly accompanied by other cardiovascular disease (CVD) risk factors, such as hypertension, obesity, and dyslipidemia. Furthermore, CVD is the most common cause of death in people with T2DM. It is therefore of critical importance to minimize the risk of macrovascular complications by carefully managing modifiable CVD risk factors in patients with T2DM. Therapeutic strategies should include lifestyle and pharmacological interventions targeting hyperglycemia, hypertension, dyslipidemia, obesity, cigarette smoking, physical inactivity, and prothrombotic factors. This article discusses the impact of modifying these CVD risk factors in the context of T2DM; the clinical evidence is summarized, and current guidelines are also discussed. The cardiovascular benefits of smoking cessation, increasing physical activity, and reducing low-density lipoprotein cholesterol and blood pressure are well established. For aspirin therapy, any cardiovascular benefits must be balanced against the associated bleeding risk, with current evidence supporting this strategy only in certain patients who are at increased CVD risk. Although overweight, obesity, and hyperglycemia are clearly associated with increased cardiovascular risk, the effect of their modification on this risk is less well defined by available clinical trial evidence. However, for glucose-lowering drugs, further evidence is expected from several ongoing cardiovascular outcome trials. Taken together, the evidence highlights the value of early intervention and targeting multiple risk factors with both lifestyle and pharmacological strategies to give the best chance of reducing macrovascular complications in the long term.

Keywords: cardiovascular risk, hypertension, obesity, dyslipidemia

\section{Introduction}

A seemingly relentless increase in the incidence of diabetes ${ }^{1}$ finds us in the midst of a global diabetes epidemic. More than 382 million people are currently affected worldwide, and this number is expected to rise to 592 million by $2035 .^{2}$ The latest statistics for the US indicate that over 25 million people, or $8.3 \%$ of the population, are affected, ${ }^{3}$ and another 79 million with prediabetes are at increased risk of developing the disease. The dynamics of the diabetes epidemic are also changing rapidly. Once a disease of the West and the affluent, type 2 diabetes mellitus (T2DM) has now spread to every country in the world and is increasingly common among the less wealthy. Notably, Asia's large population and rapid economic development have made it an epicenter of the epidemic. Furthermore, rising rates of childhood obesity have resulted in T2DM becoming more common in children and adolescents, particularly in certain ethnic groups. ${ }^{2}$

Diabetes is a major risk factor for cardiovascular disease (CVD), and CVD is the most common cause of death in people with diabetes. Various studies have indicated 
that, relative to those without diabetes, the presence of diabetes significantly increases the risk (two- to fourfold) for developing $\mathrm{CVD}^{4-9}$ and of dying when CVD is present. ${ }^{9-13}$ In the US in 2004 , heart disease was noted on $68 \%$ of diabetes-related death certificates among people aged 65 years or older, and stroke was noted on $16 \% .^{3}$ Although rates of death attributable to CVD have declined in people with and without diabetes, ${ }^{14}$ the burden of CVD in those with diabetes remains high, and implementation of preventive strategies is frequently not adequate. ${ }^{15-17}$ Individuals with prediabetes also have an increased risk of CVD. Indeed, it has been suggested that CVD risk reduction and prevention of diabetes in the prediabetes population may do more to reduce the CVD burden than aggressive treatment of CVD risk factors once diabetes has fully developed. ${ }^{18}$

T2DM is associated with clustered risk factors for CVD. Adults with diabetes have a 77\%-87\% prevalence of hypertension, a 74\%-81\% prevalence of elevated lowdensity lipoprotein cholesterol (LDL-C), and a 62\%-67\% prevalence of obesity. ${ }^{19}$ The increased risk of CVD in patients with diabetes is related in part to this high prevalence of other CVD risk factors. The management of modifiable CVD risk factors, including hyperglycemia, hypertension, dyslipidemia, obesity, cigarette smoking, and physical inactivity, is therefore critical to minimizing the risk of macrovascular complications of diabetes.

Although critically important, these traditional risk factors do not fully explain the excess risk for CVD in people with diabetes, and there have also been efforts to identify and understand the link between diabetes and other "nontraditional" CVD risk factors, such as endothelial dysfunction, impaired fibrinolysis, inflammation, microalbuminuria, increased homocysteine levels, and vascular wall abnormalities. An assessment of the clinical utility of such nontraditional risk factors by the US Preventive Services Task Force concluded that there was insufficient evidence to recommend using them to assess CVD risk in the general population. ${ }^{20,21}$ Although there is some evidence regarding their role in diabetes, ${ }^{22-24}$ it has not been conclusively determined whether it is of clinical benefit to screen for or therapeutically target these nontraditional risk factors, and their management has not been incorporated into diabetes guidelines. This article will therefore focus on how the modification of traditional risk factors impacts CVD risk in patients with T2DM, and discuss current guidelines in this regard.

\section{Lifestyle interventions}

Lifestyle management is universally advocated for prevention as well as management of T2DM. Lifestyle interventions generally include healthy eating, increased physical activity, and cessation of smoking. Such interventions have several beneficial effects, and can also have an impact on CVD risk.

\section{Weight loss}

Weight loss is advised for all overweight or obese patients with T2DM. Recommended strategies to reduce weight include regular physical activity and maintaining a healthy eating pattern. ${ }^{25-27}$ An association between overweight/obesity and an increased risk of CVD is well established in the general population. ${ }^{28}$ Furthermore, studies have shown that overweight and obesity, particularly visceral obesity, increase the risk of developing T2DM. ${ }^{29,30}$ The presence of inflammation leading to insulin resistance has been proposed as the mechanistic link between obesity and diabetes. ${ }^{31,32}$ In the context of T2DM, the relationship between weight change and CVD risk is complicated by the issue of how to adjust for such confounding factors as hypertension, dyslipidemia, and hyperglycemia, and conflicting results have made it difficult to conclusively state that weight loss is linked with a reduction in CVD risk. Nevertheless, other benefits of weight loss have been clearly demonstrated (eg, improvements in quality of life, insulin resistance, and other CVD risk factors), and clinical guidelines therefore continue to recommend weight loss for overweight or obese individuals with T2DM.

Look AHEAD (Action for Health in Diabetes; see Table 1 for full trial names) tested the hypothesis that weight loss in patients with T2DM could reduce the risk of CV events. ${ }^{33}$ Participants were randomized to an intensive lifestylemodification program of caloric restriction combined with 175 minutes per week of moderate-intensity physical activity, or to a standard program of diabetes education. Although intensive lifestyle intervention was associated with significant weight loss and improvements in several CVD risk factors, there was no effect on the rate of $\mathrm{CV}$ events during long-term follow-up, and the trial was stopped for reasons of futility after a median follow-up of almost 10 years. ${ }^{33}$ The authors proposed the possibility that a sustained weight loss of more than that achieved in the intervention group may be required to reduce the risk of CVD. Furthermore, the mean loss of $3.5 \%$ of body weight in the control group is not typical of routine care, and may have contributed to the lower-than-expected $\mathrm{CV}$ event rate. The difference between groups may also have been reduced by an increased use of potentially cardioprotective drugs in the control group, as well as the provision of educational sessions. It may also be possible that any effect of lifestyle interventions on $\mathrm{CV}$ outcomes requires more than 10 years to become apparent, and would therefore not 
Table I Trials and titles

\begin{tabular}{|c|c|c|}
\hline Trial & Title & Registration (if available) \\
\hline ACCEPT-D & Aspirin and simvastatin combination for cardiovascular events prevention trial in diabetes & ISRCTN48I I008I \\
\hline ACCOMPLISH & $\begin{array}{l}\text { Avoiding cardiovascular events through combination therapy in patients living } \\
\text { with systolic hypertension }\end{array}$ & NCT00I70950 \\
\hline ACCORD & Action to control cardiovascular risk in diabetes & NCT00000620 \\
\hline ACE & Acarbose cardiovascular evaluation trial & NCT00829660 \\
\hline ADVANCE & $\begin{array}{l}\text { Action in diabetes and vascular disease: Preterax and Diamicron - modified } \\
\text { release controlled evaluation }\end{array}$ & NCT00I 45925 \\
\hline AleCardio & $\begin{array}{l}\text { A study with aleglitazar in patients with a recent acute coronary syndrome and } \\
\text { type } 2 \text { diabetes mellitus }\end{array}$ & NCT0I042769 \\
\hline AlePrevent & $\begin{array}{l}\text { A study of aleglitazar in patients with stable cardiovascular disease and glucose } \\
\text { abnormalities }\end{array}$ & NCT0I7I58I8 \\
\hline ALLHAT & Antihypertensive and lipid-lowering treatment to prevent heart attack trial & NCT00000542 \\
\hline ASCEND & A study of cardiovascular events in diabetes & NCT00I35226 \\
\hline CANVAS & Canagliflozin cardiovascular assessment study & NCT0I032629 \\
\hline CARMELINA & $\begin{array}{l}\text { Cardiovascular and renal microvascular outcome study with linagliptin in patients } \\
\text { with type } 2 \text { diabetes mellitus at high vascular risk }\end{array}$ & NCT0I897532 \\
\hline CAROLINA & $\begin{array}{l}\text { Cardiovascular outcome study of linagliptin versus glimepiride in patients with } \\
\text { type } 2 \text { diabetes }\end{array}$ & NCT0I 243424 \\
\hline DCCT & Diabetes control and complications trial & NCT003608I5 \\
\hline DECLARE-TIMI 58 & $\begin{array}{l}\text { Multicenter trial to evaluate the effect of dapagliflozin on the incidence of } \\
\text { cardiovascular events }\end{array}$ & NCT0I730534 \\
\hline EDIC & Epidemiology of diabetes interventions and complications & NCT00360893 \\
\hline ELIXA & $\begin{array}{l}\text { Evaluation of cardiovascular outcomes in patients with type } 2 \text { diabetes after acute } \\
\text { coronary syndrome during treatment with AVE } 0010 \text { (lixisenatide) }\end{array}$ & NCT0I I 47250 \\
\hline EMPA-REG OUTCOME & Empagliflozin cardiovascular outcome event trial & NCT0II3I676 \\
\hline EXAMINE & $\begin{array}{l}\text { Examination of cardiovascular outcomes with alogliptin versus standard of care } \\
\text { in patients with type } 2 \text { diabetes mellitus and acute coronary syndrome }\end{array}$ & NCT00968708 \\
\hline EXSCEL & Exenatide study of cardiovascular event lowering trial & NCT0II44338 \\
\hline GRAND 306 & $\begin{array}{l}\text { Study of tak-875 in adults with type } 2 \text { diabetes and cardiovascular disease or risk } \\
\text { factors for cardiovascular disease }\end{array}$ & NCT0I609582 \\
\hline LEADER & $\begin{array}{l}\text { Liraglutide effect and action in diabetes: evaluation of cardiovascular outcome } \\
\text { results - a long term evaluation }\end{array}$ & NCT0II 79048 \\
\hline Look AHEAD & Look AHEAD: action for health in diabetes & NCT000I7953 \\
\hline MRFIT & Multiple risk factor intervention trial & NCT00000487 \\
\hline ONTARGET & Ongoing telmisartan alone and in combination with ramipril global endpoint trial & NCT00I53I0I \\
\hline ORIGIN & Outcome reduction with initial glargine intervention & NCT00069784 \\
\hline PLATO & The platelet inhibition and patient outcomes trial & NCT00391872 \\
\hline REWIND & Researching cardiovascular events with a weekly incretin in diabetes & NCT0I394952 \\
\hline SAVOR-TIMI 53 & $\begin{array}{l}\text { Saxagliptin assessment of vascular outcomes recorded in patients with diabetes } \\
\text { mellitus - thrombolysis in myocardial infarction } 53 \text { study }\end{array}$ & NCT0I 107886 \\
\hline Steno-2 & $\begin{array}{l}\text { Intensified multifactorial intervention in patients with type } 2 \text { diabetes and } \\
\text { microalbuminuria }\end{array}$ & NCT00320008 \\
\hline SUSTAIN 6 & $\begin{array}{l}\text { Trial to evaluate cardiovascular and other long-term outcomes with semaglutide } \\
\text { in subjects with type } 2 \text { diabetes }\end{array}$ & NCT0I720446 \\
\hline TECOS & Trial evaluating cardiovascular outcomes with sitagliptin & NCT00790205 \\
\hline T-emerge 8 & $\begin{array}{l}\text { A study of taspoglutide in patients with inadequately controlled diabetes mellitus } \\
\text { type } 2 \text { and cardiovascular disease }\end{array}$ & NCT0I0I8I73 \\
\hline TIDE & Thiazolidinedione intervention with vitamin D intervention study & NCT00879970 \\
\hline TOSCA IT & Thiazolidinediones or sulphonylureas and cardiovascular accidents intervention trial & NCT00700856 \\
\hline TRITON-TIMI 38 & $\begin{array}{l}\text { Trial to assess improvement in therapeutic outcomes by optimizing platelet inhibition } \\
\text { with prasugrel - thrombolysis in myocardial infarction }\end{array}$ & NCT0009759I \\
\hline UKPDS & United Kingdom prospective diabetes study & \\
\hline VADT & Veterans Affairs and diabetes trial & NCT00032487 \\
\hline
\end{tabular}

have been detected. ${ }^{34}$ Nevertheless, several other benefits of intensive lifestyle intervention were reported, including reductions in urinary incontinence, ${ }^{35}$ sleep apnea, ${ }^{36}$ and depression,,${ }^{37}$ and improvements in quality of life, ${ }^{38}$ physical functioning, ${ }^{39}$ and mobility. ${ }^{40}$ Therefore, even though significant effects on CV morbidity and mortality were not demonstrated, this finding will not change the recommendation of weight loss for overweight and obese patients with T2DM.

On the topic of weight loss, it is also important to note that all the major diabetes guidelines refer to bariatric surgery. ${ }^{25-27}$ 
The American Diabetes Association (ADA) guidelines state that bariatric surgery may be considered for adults with T2DM and a body mass index (BMI) $>35 \mathrm{~kg} / \mathrm{m}^{2}$, especially if the T2DM or associated comorbidities are difficult to control with lifestyle and pharmacological therapy. ${ }^{25}$ Similarly, the American Association of Clinical Endocrinologists (AACE) guidelines state that bariatric surgery should be considered for patients with a $\mathrm{BMI} \geq 35 \mathrm{~kg} / \mathrm{m}^{2}$ and comorbidities, especially if therapeutic goals have not been reached using other strategies. ${ }^{26}$ European diabetes guidelines mention that in obese individuals, bariatric surgery causes long-term weight loss and reduces the rate of incidence of T2DM and mortality. ${ }^{27}$ Several studies have shown that bariatric surgery leads to near-normalization of hyperglycemia or remission of T2DM in $40 \%-95 \%$ of patients, although the mechanisms underlying these metabolic effects of bariatric surgery are unclear. ${ }^{41-48}$ Some evidence also suggests that bariatric surgery is associated with reduced cardiovascular events and mortality. However, this is based on results from a nonrandomized study in which the control group was contemporaneously matched and differed by several characteristics at baseline. ${ }^{49,50}$ Therefore, the impact of bariatric surgery on cardiovascular risk is unclear, and appropriately controlled studies are required to clearly assess any impact.

\section{Physical activity}

Physical activity is recommended as part of weight-loss strategies, and the effects of weight loss on CVD risk were discussed in the previous section. However, physical activity is also thought to influence CVD risk independently of weight loss. The potential mechanisms underlying this link include decreased systemic inflammation, improved early diastolic filling, improved endothelial vasodilator function, and decreased abdominal visceral fat accumulation. ${ }^{51}$ Most studies have shown a significant relative reduction in the incidence of $\mathrm{CV}$ events in participants who are physically active and/or aerobically fit, with a recent prospective meta-analysis of 12 cohort studies concluding that higher levels of total physical activity were associated with a lower CV mortality risk in individuals with diabetes. ${ }^{52}$ Although there is considerable variation in the range of benefits reported, the recommendation to incorporate at least 150 minutes per week of moderate (to vigorous) ${ }^{27}$ aerobic physical activity, in addition to resistance training at least twice a week, remains a cornerstone of T2DM management and prevention of CVD in T2DM. ${ }^{25,27}$

\section{Smoking}

A large body of evidence has established a causal link between cigarette smoking and health risks in the general population.
In patients with T2DM, studies also consistently demonstrate that smoking is a risk factor for mortality and coronary heart disease, and to a lesser extent for stroke. ${ }^{53-59}$ MRFIT (Multiple Risk Factor Intervention Trial) quantified an independent and increasing risk of coronary heart disease mortality based on the number of cigarettes smoked per day. ${ }^{60}$ Although several studies have shown the benefits of quitting smoking in patients with diabetes, the potential consequence of weight gain may discourage patients from attempting to quit. A recent study investigating the link between smoking cessation and weight gain demonstrated $\mathrm{CV}$ benefits of smoking cessation in adults without diabetes, despite subsequent weight gain. The same trend was demonstrated for patients with diabetes, although it did not reach statistical significance, possibly because of limited study power. ${ }^{61}$ Diabetes guidelines universally recommend that all patients should be advised not to smoke, and that smoking-cessation counseling and other forms of treatments should be included as routine components of diabetes care. ${ }^{25,27}$

\section{Glucose control}

In the context of elevated blood glucose, the function of the vascular endothelium is altered in ways that promote atherosclerosis (reviewed in Bornfeldt and Tabas ${ }^{62}$ ). While epidemiological and pathophysiological studies clearly support the hypothesis that hyperglycemia is associated with an increased risk of CVD, they do not directly address whether interventions to improve hyperglycemia reduce this risk. ${ }^{63}$ Historically, one of the most contentious issues in the diabetes field is whether improved glycemic control is associated with a reduction in CVD, and following on from that, where glycated hemoglobin $\left(\mathrm{HbA}_{1 \mathrm{c}}\right)$ targets should be set.

In type 1 diabetes mellitus, DCCT (Diabetes Control and Complications Trial) showed a trend towards a lower risk of $\mathrm{CV}$ events with intensive glucose control, but the number of events was small and the result was not statistically significant. ${ }^{64}$ However, EDIC (Epidemiology of Diabetes Interventions and Complications), a 9-year follow-up of the DCCT cohort, showed that participants who were initially randomized to the intensive glucose-control arm had a $42 \%$ reduction of $\mathrm{CV}$ outcomes (95\% confidence interval [CI] 9\%-63\%) and a 57\% reduction in the risk of nonfatal myocardial infarction, stroke, or CV death (95\% CI 12\%-79\%). ${ }^{65}$ These findings demonstrate that an initial period of intensive glucose control had a sustained beneficial effect on CVD risk. The mechanisms underlying this legacy effect are not fully understood. A follow-up of the EDIC cohort 15 years after the study stopped found no significant difference between 
the intensive- and standard-care groups in terms of cardiac function or remodeling assessed by cardiac magnetic resonance imaging. ${ }^{66}$

Such remarkable CV benefits have not been demonstrated in T2DM. On the one hand, in UKPDS (United Kingdom Prospective Diabetes Study), a study begun in the 1970s to compare intensive glucose control with the conventional treatment of the time in patients with newly diagnosed T2DM, there was evidence, albeit inconclusive, of a CV benefit of intensive glucose control, with a $16 \%$ reduction in the risk of myocardial infarction. ${ }^{67}$ The aim of intensive treatment was fasting plasma glucose $<6 \mathrm{mmol} / \mathrm{L}(108 \mathrm{mg} / \mathrm{dL})$, making it difficult to compare this study with more recent investigations that used $\mathrm{HbA}_{1 \mathrm{c}}$ targets. Nevertheless, a legacy effect, as seen in DCCT/EDIC, was demonstrated in the 10-year follow-up of UKPDS, with patients who were originally randomized to receive intensive glucose therapy achieving a significant reduction in the risk of myocardial infarction and all-cause mortality. ${ }^{68}$

On the other hand, two large CV outcome trials, ADVANCE (Action in Diabetes and Vascular disease: PreterAx and Diamicron - MR Controlled Evaluation $)^{69}$ and VADT (Veterans Affairs and Diabetes Trial), ${ }^{70}$ which prospectively examined the effects of intensive glucose control on macrovascular outcomes, showed no significant reduction in CVD risk with intensification of glucose control. A third trial, ACCORD (Action to Control Cardiovascular Risk in Diabetes), ${ }^{71}$ was prematurely terminated, due to increased mortality in participants randomized to an intensive glucosecontrol strategy.

Although several meta-analyses have explored this controversial relationship between glucose control and CVD, these studies are not strictly comparable, making it impossible to draw firm conclusions. In summary, improved glucose control in patients with T2DM has not been definitively shown to reduce CVD, although a trend toward benefit has been observed. Based on ACCORD, ADVANCE, and VADT, Skyler et al suggest that glucose control plays a greater role before macrovascular disease is well developed and a minimal role when it is advanced, and that significant benefit is only seen in subsets of patients with shorter T2DM duration, lower baseline $\mathrm{HbA}_{1 \mathrm{c}}$, and/or absence of known CVD. ${ }^{63}$ Furthermore, any benefit of glucose control on CVD risk in T2DM is likely to be modest compared with treatment of other CVD risk factors, and therefore difficult to demonstrate in their presence. ${ }^{63}$ This resonates with the Look AHEAD weight-loss trial, where potential $\mathrm{CV}$ benefits in the intervention group may have been masked by efficient treatment of other risk factors in the control group, and highlights an ongoing difficulty with the design of $\mathrm{CV}$ outcome trials.

Current guidelines suggest a target $\mathrm{HbA}_{1 \mathrm{c}} \leq 6.5 \%$ (AACE) or $<7.0 \%$ (ADA) for patients with short diabetes duration, long life expectancy, no significant CVD, and at low hypoglycemia risk. ${ }^{25,27}$ However, all guidelines emphasize the importance of individualization of targets, especially for patients with concurrent illness and at risk for hypoglycemia. The AACE guideline suggests a target $\mathrm{HbA}_{1 \mathrm{c}}$ of $>6.5 \%$ if lower targets cannot be achieved without adverse outcomes. ${ }^{26}$ The ADA suggests a less stringent goal (than their general target of $<7.0 \%$ ) for patients with a history of severe hypoglycemia, limited life expectancy, advanced microvascular or macrovascular complications, extensive comorbid conditions, and those with long-standing diabetes. ${ }^{25}$ Furthermore, all guidelines recognize that any comprehensive diabetes-care plan should include modification of other CVD risk factors and also provide recommendations to this effect.

Although beneficial effects of glucose control on CVD risk have not been conclusively demonstrated, the benefits of good glucose control on microvascular outcomes are unequivocal, and antihyperglycemic agents therefore remain a cornerstone of T2DM treatment. There are many such agents to choose from and several factors for the physician to consider, including safety. The CV safety of certain antihyperglycemic drugs, particularly rosiglitazone and some sulfonylureas, has been called into question. ${ }^{72,73}$ This has led to much debate and controversy, although recent studies demonstrated that rosiglitazone did not increase the risk of $\mathrm{CV}$ overall morbidity and mortality any more than other standard glucose-lowering agents. ${ }^{74,75}$ Nevertheless, partly as a result of the rosiglitazone experience, the US Food and Drug Administration (FDA) recognized the need for safety data and issued guidance in 2008 making it essential for manufacturers to demonstrate that a new antidiabetes therapy is not associated with an unacceptable increase in $\mathrm{CV}$ risk. ${ }^{76}$ As a result of this change in the regulatory landscape, several large $\mathrm{CV}$-outcome trials are ongoing or have recently been completed (Table 2).

The FDA guidance applies to drugs approved since 2008, and thus many of these trials involve incretin-based therapies (dipeptidyl peptidase-4 inhibitors and glucagonlike peptide-1 agonists) and sodium glucose cotransporter (SGLT)-2 inhibitors, as these are the most recently developed antihyperglycemic drug classes. There has been cautious optimism that incretin-based therapies may have CV benefits beyond those attributed to reducing hyperglycemia, with evidence of cardioprotective actions in preclinical models 
Table 2 Cardiovascular outcomes trials in diabetes

\begin{tabular}{|c|c|c|c|c|}
\hline Clinical Trial.gov ID & Drug & Trial short name $^{a}$ & Sample size & Start date \\
\hline \multicolumn{5}{|c|}{ Sodium glucose cotransporter 2 (SGLT2) inhibitors } \\
\hline NCT0I03262983 & Canagliflozin & CANVAS & 4,330 & Dec 2009 \\
\hline NCT0II3I676 & Empagliflozin & EMPA-REG OUTCOME & 7,000 & Jul 2010 \\
\hline NCT0I730534 & Dapagliflozin & DECLARE-TIMI 58 & 17,150 & Apr 2013 \\
\hline NCT0I98688I & Ertugliflozin & & 3,900 & Nov 2013 \\
\hline \multicolumn{5}{|c|}{ Dipeptidyl peptidase-4 (DPP-4) inhibitors } \\
\hline NCT00790205 & Sitagliptin & TECOS & 14,000 & Dec 2008 \\
\hline NCT00968708 & Alogliptin & EXAMINE & 5,380 & Oct $2009^{b}$ \\
\hline NCT0I I0788681 & Saxagliptin & SAVOR-TIMI 53 & 16,492 & May $2010^{b}$ \\
\hline NCTOI $243424^{84}$ & Linagliptin & CAROLINA & 6,000 & Oct 2010 \\
\hline NCT0I703208 & MK-3I02 & & 4,000 & Oct 2012 \\
\hline NCT0I897532 & Linagliptin & CARMELINA & 8,300 & Jul 2013 \\
\hline \multicolumn{5}{|c|}{ Glucagon like peptide-I (GLP-I) agonists } \\
\hline NCT0I0I8I73 & Taspoglutide & T-emerge 8 & 2,118 & $\operatorname{Jan} 2010^{c}$ \\
\hline NCT0II 47250 & Lixisenatide & ELIXA & 6,000 & Jun 2010 \\
\hline NCTOII 44338 & Exenatide & EXSCEL & 14,000 & Jun 2010 \\
\hline NCTOII $79048^{85}$ & Liraglutide & LEADER & 9,340 & Aug 2010 \\
\hline NCT0I394952 & Dulaglutide & REWIND & 9,622 & Jul 20II \\
\hline NCT0I720446 & Semaglutide & SUSTAIN 6 & 3,260 & Feb 2013 \\
\hline NCT0I455896 & ITCA 650 & & 2,000 & Mar 2013 \\
\hline \multicolumn{5}{|l|}{ Others } \\
\hline NCT0070085686 & Pioglitazone versus SU & TOSCA IT & $3,37 \mid$ & Sep 2008 \\
\hline NCT00879970 & Rosiglitazone/pioglitazone & TIDE & I,332 & May $2009^{c}$ \\
\hline NCT0I04276988 & Aleglitazar & AleCardio & 7,228 & $\operatorname{Jan} 2010^{c}$ \\
\hline NCT0I7I58I8 & Aleglitazar & AlePrevent & I,999 & $\operatorname{Dec} 2012^{c}$ \\
\hline NCT00069784 ${ }^{89}$ & Insulin glargine & ORIGIN & 12,537 & Aug $2003^{b}$ \\
\hline NCT0I959529 & Insulin degludec & & 7,500 & Oct 2013 \\
\hline NCT00829660 & Acarbose & $\mathrm{ACE}$ & 7,500 & Feb 2009 \\
\hline NCT0I609582 & Fasiglifam (TAK-875) & GRAND 306 & 5,000 & Jun 2012 \\
\hline
\end{tabular}

Notes: aFor full trial names see Table I; bcompleted; 'terminated.

of CV dysfunction and beneficial effects on cardiac function in short-term clinical studies of ischemic heart disease. ${ }^{77-79}$ However, this optimism has been tempered by results of SAVOR-TIMI (Saxagliptin Assessment of Vascular Outcomes Recorded in patients with diabetes mellitus Thrombolysis in Myocardial Infarction) 53 and EXAMINE (EXamination of cArdiovascular outcoMes with alogliptIN versus standard of carE in patients with type 2 diabetes mellitus and acute coronary syndrome), which demonstrated the safety of saxagliptin and alogliptin, respectively, but failed to show a benefit on CV outcomes in either case. ${ }^{80,81}$ Therefore, while early studies for SGLT2 inhibitors also suggest they may have beneficial effects on CVD risk (in particular, as they are associated with lowering blood pressure and inducing weight loss), ${ }^{82}$ the ongoing $\mathrm{CV}$-outcome trials are essential to provide conclusive information on clinical outcomes (see Table 2).

\section{Blood pressure control}

The pathophysiological relationship between hypertension and diabetes is complex and not well understood.
Evidence suggests that insulin resistance plays a significant role in the interplay between diabetes, hypertension, and CVD, but such comorbidities as obesity and dyslipidemia make it difficult to decipher the common pathological mechanisms. Nevertheless, various studies indicate that the presence of hypertension is a very strong driver of CV outcomes in individuals with diabetes. ${ }^{90,91}$ Further evidence suggests that CVD risk starts to increase above a blood pressure of $115 / 75$, and is then doubled for every $20 \mathrm{mmHg}$ increase in systolic blood pressure, or for every $10 \mathrm{mmHg}$ increase in diastolic blood pressure. ${ }^{92}$ In contrast to hyperglycemia, several clinical investigations have shown that lowering blood pressure in patients with hypertension and diabetes reduces the risk of cerebrovascular accidents and congestive heart failure. ${ }^{93-98}$ In spite of this evidence, hypertension is reportedly the most poorly controlled of the cardiac risk factors in this population. ${ }^{15-17}$

Furthermore, the treatment of hypertension has also raised controversies in the context of choosing blood pressure targets, with some arguments for targets of 130/80 or even lower, ${ }^{99,100}$ and others for targets below $140 / 80 \mathrm{mmHg}{ }^{101-105}$ 
This controversy is reflected in the targets recommended by different clinical practice guidelines. Until recently, various guidelines and position statements were strikingly consistent in setting a target blood pressure level at 130/80 $\mathrm{mmHg}$. However, recent guidelines on hypertension management for patients with diabetes issued by the ADA and European Society of Hypertension/European Society of Cardiology/ European Association for the Study of Diabetes include a systolic blood pressure target of $<140 \mathrm{mmHg}{ }^{25,27}$ On the other hand, the AACE algorithm maintains its recommendation of a target in the region of 130/80 mmHg. ${ }^{26}$ Table 3 shows only major US and international guidelines issued in the last three years, as these were able to take into account the most recent investigations. Although there are discrepancies between the recommendations, what is clear is that patients with diabetes should be treated to a target blood pressure of at least $<140 / 80 \mathrm{mmHg}$, but the physician will need to consider the individual's overall health when setting any further targets.

Intensive lifestyle intervention may be sufficient to lower blood pressure in patients with mild hypertension. ${ }^{25-27}$ However, additional pharmacological intervention will be required for most patients. A wide variety of blood pressure-lowering agents, including angiotensin-converting enzyme inhibitors (ACE-Is), angiotensin-receptor blockers (ARBs), $\beta$-blockers, diuretics, and calcium-channel blockers, have been shown to be effective in reducing the risk of CV events. The Seventh Report of the Joint National Committee on Prevention, Detection, Evaluation, and Treatment of High Blood Pressure recommended a thiazide diuretic as the first line of treatment. ${ }^{108}$ This guidance was based on the findings of ALLHAT

Table 3 Recommended blood pressure targets

\begin{tabular}{|c|c|}
\hline Issuing organization & Blood pressure target $(\mathrm{mmHg})$ \\
\hline American Diabetes Association ${ }^{25}$ & $\begin{array}{l}<140 / 80 \\
<130 / 80 \text { may be appropriate } \\
\text { for certain individuals, such as } \\
\text { younger patients, if achievable } \\
\text { without undue treatment burden }\end{array}$ \\
\hline $\begin{array}{l}\text { American Association of Clinical } \\
\text { Endocrinologists }^{26}\end{array}$ & $\sim 130 / 80$ \\
\hline $\begin{array}{l}\text { European Society of Cardiology/ } \\
\text { European Association for the } \\
\text { Study of Diabetes }{ }^{27}\end{array}$ & $<140 / 85$ \\
\hline $\begin{array}{l}\text { European Society of Hypertension/ } \\
\text { European Society of Cardiology }{ }^{106}\end{array}$ & $<140 / 85$ \\
\hline International Diabetes Federation ${ }^{107}$ & $\begin{array}{l}\leq 130 / 80 \\
\text { Revise target upward in elderly } \\
\text { or if there is significant risk of } \\
\text { postural hypotension and falls }\end{array}$ \\
\hline
\end{tabular}

(Antihypertensive and Lipid-Lowering Treatment to Prevent Heart Attack Trial), which showed that chlorthalidone was superior to other agents in preventing heart failure. ${ }^{109}$ However, many other studies provide evidence that blockade of the renin-angiotensin-aldosterone system (RAAS) with an ACE-I or an ARB is particularly valuable for the treatment of hypertension in T2DM patients with high CVD risk. ${ }^{110-118}$

The most up-to-date diabetes guidelines recommend an ACE-I or ARB as the first line of therapy. ${ }^{25-27}$ Multiple drug therapy is generally required to achieve blood pressure targets, although ACE-I/ARB combinations are not recommended, as ONTARGET (Ongoing Telmisartan Alone and in combination with Ramipril Global Endpoint Trial) showed they are associated with an increased risk of renal failure and hyperkalemia. ${ }^{119}$ The AACE algorithm for CVD riskfactor modification recommends dual therapy with an RAAS blocker and a thiazide, calcium-channel blocker, or $\beta$-blocker when blood pressure is $>150 / 100 \mathrm{mmHg}$, or when goals are not met. ${ }^{26}$ RAAS blockade is usually the cornerstone of combination therapy, with a thiazide diuretic or a calcium-channel blocker often recommended as an add-on. ACCOMPLISH (Avoiding Cardiovascular events through COMbination therapy in Patients Living with Systolic Hypertension) compared these combinations, and showed superiority of an ACE-I/ calcium-channel blocker combination over an ACE-I/thiazide diuretic combination. ${ }^{120}$ In light of these findings, a combination of an RAAS blocker and a calcium-channel blocker is often proposed as a first choice. ${ }^{121}$ However, this should not imply that other combinations are ineffective or harmful. ${ }^{122}$ Indeed, there is such an array of antihypertensive options that the choice may be bewildering; however, a meta-analysis of 27 randomized trials concluded that all of the major classes of blood pressure-lowering agents are likely to substantially reduce CV risk. ${ }^{123}$ This emphasizes the priority of blood pressure lowering per se, regardless of the choice of drug class. Nevertheless, individualization is always appropriate, eg, patients with heart failure could benefit from $\beta$-blockers, those with proteinuria from RAAS blockade, those with prostatism from $\alpha$-blockers, and those with coronary artery disease from $\beta$-blockers or calcium-channel blockers. ${ }^{26}$

\section{Dyslipidemia}

Dyslipidemia is strikingly common in patients with T2DM. The altered lipid profile associated with T2DM is most commonly attributed to insulin resistance, ${ }^{124,125}$ and is generally characterized by a high concentration of plasma triglycerides, low concentration of high-density lipoprotein cholesterol (HDL-C), and increased concentration of 
small dense LDL-C particles. A multivariate analysis from UKPDS found that an increased concentration of LDL-C was the strongest independent predictor of CVD, followed by decreased concentrations of HDL-C. ${ }^{55}$ Indeed, several studies have shown that lowering LDL-C (usually with statins) reduces the risk of major $\mathrm{CV}$ events in patients with diabetes. ${ }^{126-132}$ While HDL-C is a strong CVD risk predictor, numerous studies of pharmacological interventions to raise HDL-C have not found evidence of a beneficial effect on CV risk. ${ }^{133-137}$ Similarly, although there is an association between elevated triglycerides and CVD, the degree to which triglycerides directly promote CVD has long been debated. Currently, very little clinical evidence exists to show that lowering triglycerides leads to a reduction of CVD risk, ${ }^{138}$ although in the ACCORD lipid trial, a subgroup of patients who had the highest baseline triglyceride level and lowest HDL-C baseline level appeared to benefit from combination therapy with a statin plus a fibrate. ${ }^{135}$

In 2004, the US National Cholesterol Education Panel Adult Panel III guidelines emphasized the importance of lowering elevated levels of LDL-C as the most effective treatment to reduce the incidence of coronary heart disease mortality and morbidity. ${ }^{139}$ Management of LDL-C concentrations remains a major goal of diabetes treatment, with current guidelines emphasizing lowering LDL-C to a target goal of $<100 \mathrm{mg} / \mathrm{dL}$ for T2DM patients without overt CVD. ${ }^{25-27}$ Lifestyle interventions along with improved glycemic control may allow some patients to reach this lipid goal; however, pharmacological agents should be added if there is an inadequate response to lifestyle modifications, or in cases of high CVD risk. In patients with overt CVD or older than 40 years with other CVD risk factors, pharmacological treatment should be added to lifestyle therapy regardless of baseline lipid levels; an LDL-C target of $<70 \mathrm{mg} / \mathrm{dL}$ is appropriate for such highrisk patients. ${ }^{25-27}$ If statin-treated patients do not reach targets on maximum tolerated doses, the ADA guideline suggests a $30 \%-40 \%$ LDL-C reduction from baseline as an acceptable alternative target, while other guidelines recommend at least $\mathrm{a} \geq 50 \%$ reduction if goals cannot be reached. ${ }^{27}$ Statins are the drug of choice for lowering LDL-C; however, the ADA guideline also mentions additional LDL-C-lowering agents, including niacin, fenofibrate, ezetimibe, and bile-acid sequestrants, and these are included in the AACE CVD risk factormodification algorithm as options to be used in combination with a statin to lower LDL-C. ${ }^{26}$ However, without evidence that such combination therapy provides any significant improvement in CVD risk reduction, this approach is not broadly recommended by the ADA.
Although it is unclear whether modifying HDL-C and triglyceride levels impacts CVD risk, target goals for these parameters have nevertheless been incorporated into ADA and AACE guidelines, with both recommending lifestyle modifications and referring to the use of omega-3 fish oil, fibrates, and niacin to achieve target triglyceride levels $<150$ $\mathrm{mg} / \mathrm{dL} .^{25,26}$ The ADA guideline states that HDL-C targets of $>40 \mathrm{mg} / \mathrm{dL}$ in men and $>50 \mathrm{mg} / \mathrm{dL}$ in women are desirable, and mentions the use of niacin and fibrates to increase HDL-C levels, even though their effect on CVD outcomes in patients with diabetes is unclear. The AACE CVD risk factor-modification algorithm proposes a non-HDL-C (total cholesterol minus HDL-C) level of $<130 \mathrm{mg} / \mathrm{dL}$, and also identifies fibrates, niacin, and omega-3 fish oil as treatment options.

Although it is encouraging to note that the proportion of patients meeting LDL-C goals has improved over time, recent analyses indicate that LDL-C levels remain uncontrolled in over $45 \%$ of patients with T2DM. ${ }^{140,141}$ Intensification of efforts to achieve lipid goals in clinical practices therefore provides an opportunity to have an impact on overall $\mathrm{CV}$ risk in patients with diabetes.

\section{Antiplatelet therapy}

Prothrombotic and fibrinolytic mechanisms are tightly regulated under normal circumstances, such that there is protection from bleeding without the formation of pathological thrombosis. However, in patients with diabetes, this regulation is disrupted, and there is an increased thrombotic tendency, due to platelet hyperreactivity, decreased fibrinolysis, and increased activation of prothrombotic coagulation factors (eg, tissue factor, factor VIII, thrombin, fibrinogen, plasminogen-activator inhibitor 1). ${ }^{142,143}$ A number of antiplatelet agents have been shown to be of benefit for the prevention of $\mathrm{CV}$ events in certain groups, with aspirin being the most commonly used. Aspirin inhibits thromboxane $\mathrm{A}_{2}$-dependent platelet activation and aggregation by way of its irreversible inhibition of cyclooxygenase 1 , and a number of studies have demonstrated that treatment with low-dose aspirin resulted in a significant reduction of serious vascular events in patients with diabetes and CVD. ${ }^{144-146}$

The evidence regarding the use of aspirin for primary prevention of $\mathrm{CV}$ events in adults with diabetes is more controversial. For example, two recent randomized controlled trials did not show a significant CV benefit of aspirin in patients with diabetes. ${ }^{147,148}$ These trials were included in a recent metaanalysis that also incorporated data from seven other trials, either performed specifically in patients with diabetes, or that 
included subgroups of patients with diabetes. ${ }^{149}$ Across trials, aspirin was associated with a $9 \%$ decrease in risk of coronary events and a $10 \%$ reduction in the risk of stroke; however, the decrease in risk for both outcomes did not reach statistical significance. These results are consistent with the findings of other meta-analyses, ${ }^{150-154}$ and together they suggest that aspirin may produce a modest reduction in the risk of $\mathrm{CV}$ events in patients with diabetes. However, aspirin use is also associated with a significant increase in the risk of intracranial and extracranial hemorrhage, and the relative trade-off between $\mathrm{CV}$ events prevented by aspirin and bleeding events caused by aspirin therefore needs careful consideration. ${ }^{149}$ Further studies are required to assess more reliably the benefit-to-risk ratio of aspirin in primary prevention in T2DM patients at moderate CV risk. To address this, ACCEPT-D (Aspirin and simvastatin Combination for Cardiovascular Events Prevention Trial in Diabetes) ${ }^{155}$ and ASCEND (A Study of Cardiovascular Events iN Diabetes) are two large ongoing trials that collectively will include more than 15,000 participants with diabetes. These investigations will provide important information about the role of aspirin for primary prevention in patients with diabetes, and may help identify which patients are at greatest risk, and therefore which patients stand to derive a net benefit from aspirin therapy.

Platelet $\mathrm{P} 2 \mathrm{Y}_{12}$-receptor blockers are an alternative class of antiplatelet agents that include clopidogrel, prasugrel, and ticagrelor. Clopidogrel inhibits adenosine diphosphatedependent platelet function by irreversible inhibition of the platelet $\mathrm{P} 2 \mathrm{Y}_{12}$ receptor, and has proven clinical efficacy in reducing $\mathrm{CV}$ events in patients with diabetes. ${ }^{156}$ However, its inhibition is less predictable than the inhibition of thromboxane $\mathrm{A}_{2}$-dependent platelet activation by aspirin, and genetic variation of relevant liver enzymes, as well as drug-drug interactions with proton-pump inhibitors, can affect clopidogrel's mechanism of action, leading to a variable clinical response to treatment. ${ }^{157}$ Furthermore, various studies suggest a clinically relevant suboptimal clopidogrel response in at least some patients with diabetes. ${ }^{158}$

Prasugrel also exerts its antiplatelet effect by irreversible inhibition of the $\mathrm{P} 2 \mathrm{Y}_{12}$ receptor; however, it leads to platelet inhibition more rapidly and with less variability compared with clopidogrel. It is currently indicated for the reduction of thrombotic $\mathrm{CV}$ events (including stent thrombosis) in patients with acute coronary syndrome who are to be managed with percutaneous coronary intervention. TRITON-TIMI (TRial to assess Improvement in Therapeutic Outcomes by optimizing platelet inhibitioN with prasugrel - Thrombolysis In Myocardial Infarction)
38 demonstrated that prasugrel produced a greater reduction in ischemic events than clopidogrel, but was associated with an increased risk of bleeding in patients with acute coronary syndrome undergoing percutaneous coronary intervention. ${ }^{159}$ Interestingly, a subgroup of patients with T2DM derived the highest benefit from prasugrel without an increased risk of major bleeding. ${ }^{160}$ On the other hand, another study that compared prasugrel with clopidogrel in the context of acute coronary syndromes without revascularization did not demonstrate an increased benefit of prasugrel for reducing ischemic events in the general cohort or in a diabetes subgroup; furthermore, similar risks of bleeding were observed with both antiplatelet agents. ${ }^{161}$

Ticagrelor also inhibits $\mathrm{P} 2 \mathrm{Y}_{12}$ receptors, but differs from clopidogrel and prasugrel by virtue of its direct and reversible mechanism of action. PLATO (Platelet Inhibition And Patient Outcomes) demonstrated that ticagrelor was more effective than clopidogrel in reducing death from $\mathrm{CV}$ causes and total mortality in a general postacute coronary syndrome cohort, ${ }^{162}$ and decreased ischemic events in diabetes patients without increasing the risk of bleeding. ${ }^{163}$ In a recent small study (30 patients) that compared ticagrelor and prasugrel in acute coronary syndrome patients with diabetes, ticagrelor achieved a significantly higher platelet inhibition than prasugrel; ${ }^{164}$ however, no clinical relevance of these findings has so far been demonstrated.

Current guidelines recommend aspirin therapy as a potential primary prevention strategy in those with diabetes who are at increased CVD risk and who are not at increased risk for bleeding. ${ }^{25,27}$ However, a net benefit of aspirin use for the primary prevention of CVD has not been unequivocally demonstrated, and thus aspirin is no longer recommended for those with diabetes at low CVD risk. ${ }^{25,27,149}$ Low-dose aspirin therapy (75-162 mg/day) is recommended as a secondary prevention strategy in those with diabetes with a history of CVD, and clopidogrel as an alternative therapy in aspirinintolerant patients. ${ }^{25,27}$ Use of a $\mathrm{P} 2 \mathrm{Y}_{12}$-receptor antagonist in combination with aspirin for at least 1 year in patients following acute coronary syndrome is recommended by the ADA. The ADA guideline also draws attention to the fact that evidence supports the use of either ticagrelor or clopidogrel if no percutaneous coronary intervention was performed, and the use of clopidogrel, ticagrelor, or prasugrel if percutaneous coronary intervention was performed..$^{25}$ The prescribing information for both ticagrelor and prasugrel contains a boxed warning regarding bleeding risk, ${ }^{165,166}$ and caution is therefore urged in patients with a high risk for bleeding. 


\section{Multifactorial approaches}

Evidence suggests that targeted multifactorial intervention is of benefit for reducing CVD in the context of T2DM. In Steno-2 (Intensified Multifactorial Intervention in Patients with Type 2 Diabetes and Microalbuminuria), patients with T2DM and persistent microalbuminuria were randomized to receive either conventional intervention involving multiple risk factors, or intensified, targeted, multifactorial intervention involving a combination of medications and focused behavior modification. ${ }^{167}$ Targets for $\mathrm{HbA}_{1 \mathrm{c}}$, systolic and diastolic blood pressure, and fasting values of serum total cholesterol, LDL-C, and triglycerides were lower in the intensified-intervention group than with conventional intervention. Although only $15 \%$ of patients in the intensive arm reached the $\mathrm{HbA}_{1 \mathrm{c}}$ target of $<6.5 \%$, the risk of vascular complications was approximately halved in this group after a mean follow-up of 7.8 years. Few patients achieved all treatment goals (approximately 70\% reached the total cholesterol target of $<175 \mathrm{mg} / \mathrm{dL}$, approximately $58 \%$ reached the triglyceride target of $<150 \mathrm{mg} / \mathrm{dL}$, almost $50 \%$ reached the systolic blood pressure goal of $<130 \mathrm{mmHg}$, and approximately $70 \%$ reached the diastolic blood pressure goal of $<80 \mathrm{mmHg}$ ). ${ }^{167}$ Nevertheless, for most patients, the treatment goals for lipids and blood pressure were achievable without undue difficulties. ${ }^{168}$

At the end of this study, all patients in both groups were informed in detail about the benefits of intensified multifactorial treatments, and the primary care providers to whom the patients were referred were educated about this approach. Patients were subsequently followed observationally for a mean of 5.5 years. This follow-up analysis demonstrated that the intensified multifactorial approach had sustained beneficial effects with respect to vascular complications: absolute mortality was reduced by $20 \%$, and CV mortality was reduced by $13 \%$ in patients originally assigned to the intensively managed group, compared with those who received conventional therapy. ${ }^{169}$ A recent study aiming to address the feasibility of a multifactorial intensive intervention in patients with $\mathrm{T} 2 \mathrm{DM}$ of at least 2 years' duration and no previous $\mathrm{CV}$ events demonstrated that such an approach is feasible and effective in clinical practice, and is associated with significant and durable improvements in CVD risk profile. ${ }^{170}$

\section{Conclusion}

Early intervention has the greatest impact on micro- and macrovascular complications of T2DM. Glycemic control therapies should be started as soon as diabetes is detected, and early intervention for blood pressure and lipids is vital.
Treatment strategies for these patients will evolve as new drugs are continually being developed. However, lifestyle changes are also essential to any management plan, and although many patients may need pharmacological therapy to reach targets, the benefits of a healthy lifestyle should not be underestimated. For a newly diagnosed patient, the range of risk factors requiring consideration may seem overwhelming. Integrated care teams incorporating diabetes educators can greatly help in this respect, providing the support patients need to make lifestyle changes, as well as adhere closely to treatment regimens. Working with the patient to target multiple risk factors with both lifestyle and pharmacological strategies needs time and effort, but gives the best chance of reducing the likelihood of microvascular and macrovascular complications in the long term.

\section{Acknowledgments}

Medical writing assistance, supported financially by Boehringer Ingelheim, was provided by Ann Kerrigan of Envision Scientific Solutions during the preparation of this review. Boehringer Ingelheim was given the opportunity to check the data used in the manuscript for factual accuracy only. The author was fully responsible for all content and editorial decisions, was involved at all stages of manuscript development, and has approved the final version of the review, which reflects the author's interpretation and conclusions.

\section{Disclosure}

Dr Lorber is a board member of Biodel; has served as a consultant for Merck, Novo Nordisk, and Janssen; has received grants from MannKind, Eli Lilly, and Boehringer Ingelheim; has received payments for lectures from Novo Nordisk and Janssen; and owns stock in Biodel.

\section{References}

1. Cheng YJ, Imperatore G, Geiss LS, et al. Secular changes in the agespecific prevalence of diabetes among US adults: 1988-2010. Diabetes Care. 2013;36(9):2690-2696.

2. International Diabetes Federation. IDF Diabetes Atlas. 6th ed. Brussels: IDF; 2013.

3. Centers for Disease Control and Prevention. National Diabetes Fact Sheet: National Estimates and General Information on Diabetes and Prediabetes in the United States. Atlanta: CDC; 2011.

4. Barrett-Connor EL, Cohn BA, Wingard DL, Edelstein SL. Why is diabetes mellitus a stronger risk factor for fatal ischemic heart disease in women than in men? The Rancho Bernardo Study. JAMA. 1991;265(5):627-631.

5. Fuller JH, Shipley MJ, Rose G, Jarrett RJ, Keen H. Mortality from coronary heart disease and stroke in relation to degree of glycaemia: the Whitehall study. Br Med J (Clin Res Ed). 1983;287(6396):867-870.

6. Kannel WB, McGee DL. Diabetes and cardiovascular disease. The Framingham study. JAMA. 1979;241(19):2035-2038.

7. Manson JE, Colditz GA, Stampfer MJ, et al. A prospective study of maturity-onset diabetes mellitus and risk of coronary heart disease and stroke in women. Arch Intern Med. 1991;151(6):1141-1147. 
8. Stamler J, Vaccaro O, Neaton JD, Wentworth D. Diabetes, other risk factors, and 12-yr cardiovascular mortality for men screened in the Multiple Risk Factor Intervention Trial. Diabetes Care. 1993;16(2):434-444.

9. Haffner SM, Lehto S, Rönnemaa T, Pyörälä K, Laakso M. Mortality from coronary heart disease in subjects with type 2 diabetes and in nondiabetic subjects with and without prior myocardial infarction. N Engl J Med. 1998;339(4):229-234.

10. Franco OH, Steyerberg EW, Hu FB, Mackenbach J, Nusselder W. Associations of diabetes mellitus with total life expectancy and life expectancy with and without cardiovascular disease. Arch Intern Med. 2007;167(11):1145-1151.

11. Behar S, Boyko V, Reicher-Reiss H, Goldbourt U. Ten-year survival after acute myocardial infarction: comparison of patients with and without diabetes. SPRINT Study Group. Secondary Prevention Reinfarction Israeli Nifedipine Trial. Am Heart J. 1997;133(3):290-296.

12. Mak KH, Moliterno DJ, Granger CB, et al. Influence of diabetes mellitus on clinical outcome in the thrombolytic era of acute myocardial infarction. GUSTO-I Investigators. Global Utilization of Streptokinase and Tissue Plasminogen Activator for Occluded Coronary Arteries J Am Coll Cardiol. 1997;30(1):171-179.

13. Malmberg K, Yusuf S, Gerstein HC, et al. Impact of diabetes on long-term prognosis in patients with unstable angina and non-Q-wave myocardial infarction: results of the OASIS (Organization to Assess Strategies for Ischemic Syndromes) Registry. Circulation. 2000;102(9): 1014-1019.

14. Gregg EW, Cheng YJ, Saydah S, et al. Trends in death rates among US adults with and without diabetes between 1997 and 2006: findings from the National Health Interview Survey. Diabetes Care. 2012;35(6): 1252-1257.

15. Farkouh ME, Boden WE, Bittner V, et al. Risk factor control for coronary artery disease secondary prevention in large randomized trials. $J$ Am Coll Cardiol. 2013;61(15):1607-1615.

16. Joseph J, Svartberg J, Njølstad I, Schirmer H. Change in cardiovascular risk factors in relation to diabetes status: the Tromso Study. Eur J Prev Cardiol. 2012;19(3):551-557.

17. Saydah SH, Fradkin J, Cowie CC. Poor control of risk factors for vascular disease among adults with previously diagnosed diabetes. JAMA. 2004;291(3):335-342.

18. Haffner SM. Pre-diabetes, insulin resistance, inflammation and CVD risk. Diabetes Res Clin Pract. 2003;61 Suppl 1:S9-S18.

19. Preis SR, Pencina MJ, Hwang SJ, et al. Trends in cardiovascular disease risk factors in individuals with and without diabetes mellitus in the Framingham Heart Study. Circulation. 2009;120(3):212-220.

20. Helfand M, Buckley DI, Freeman M, et al. Emerging risk factors for coronary heart disease: a summary of systematic reviews conducted for the US. Preventive Services Task Force. Ann Intern Med. 2009;151(7): 496-507.

21. US Preventive Services Task Force. Using nontraditional risk factors in coronary heart disease risk assessment: US Preventive Services Task Force recommendation statement. Ann Intern Med. 2009;151(7):474-482.

22. Fonseca V, Desouza C, Asnani S, Jialal I. Nontraditional risk factors for cardiovascular disease in diabetes. Endocr Rev. 2004;25(1):153-175.

23. Resnick HE, Howard BV. Diabetes and cardiovascular disease. Annu Rev Med. 2002;53:245-267.

24. Muntner P, He J, Chen J, Fonseca V, Whelton PK. Prevalence of non-traditional cardiovascular disease risk factors among persons with impaired fasting glucose, impaired glucose tolerance, diabetes, and the metabolic syndrome: analysis of the Third National Health and Nutrition Examination Survey (NHANES III). Ann Epidemiol. 2004;14(9):686-695.

25. American Diabetes Association. Standards of medical care in diabetes 2014. Diabetes Care. 2014;37 Suppl 1:S14-S80.

26. Garber AJ, Abrahamson MJ, Barzilay JI, et al. American Association of Clinical Endocrinologists' comprehensive diabetes management algorithm 2013 consensus statement - executive summary. Endocr Pract. 2013;19(3):536-557.
27. Rydén L, Grant PJ, Anker SD, et al. ESC guidelines on diabetes, prediabetes, and cardiovascular diseases developed in collaboration with the EASD: the Task Force on diabetes, pre-diabetes, and cardiovascular diseases of the European Society of Cardiology (ESC) and developed in collaboration with the European Association for the Study of Diabetes (EASD). Eur Heart J. 2013;34(39):3035-3087.

28. Bogers RP, Bemelmans WJ, Hoogenveen RT, et al. Association of overweight with increased risk of coronary heart disease partly independent of blood pressure and cholesterol levels: a meta-analysis of 21 cohort studies including more than 300000 persons. Arch Intern Med. 2007;167(16):1720-1728.

29. Chan JM, Rimm EB, Colditz GA, Stampfer MJ, Willett WC. Obesity, fat distribution, and weight gain as risk factors for clinical diabetes in men. Diabetes Care. 1994;17(9):961-969.

30. Colditz GA, Willett WC, Rotnitzky A, Manson JE. Weight gain as a risk factor for clinical diabetes mellitus in women. Ann Intern Med. 1995;122(7):481-486.

31. Shoelson SE, Lee J, Goldfine AB. Inflammation and insulin resistance. J Clin Invest. 2006;116(7):1793-1801.

32. Donath MY, Shoelson SE. Type 2 diabetes as an inflammatory disease. Nat Rev Immunol. 2011;11(2):98-107.

33. Wing RR, Bolin P, Brancati FL, et al. Cardiovascular effects of intensive lifestyle intervention in type 2 diabetes. $N$ Engl J Med. 2013;369(2): $145-154$.

34. Gerstein HC. Do lifestyle changes reduce serious outcomes in diabetes? N Engl J Med. 2013;369(2):189-190.

35. Phelan S, Kanaya AM, Subak LL, et al. Weight loss prevents urinary incontinence in women with type 2 diabetes: results from the Look AHEAD trial. J Urol. 2012;187(3):939-944.

36. Foster GD, Borradaile KE, Sanders MH, et al. A randomized study on the effect of weight loss on obstructive sleep apnea among obese patients with type 2 diabetes: the Sleep AHEAD study. Arch Intern Med. 2009;169(17):1619-1626.

37. Faulconbridge LF, Wadden TA, Rubin RR, et al. One-year changes in symptoms of depression and weight in overweight/obese individuals with type 2 diabetes in the Look AHEAD study. Obesity (Silver Spring). 2012;20(4):783-793.

38. Williamson DA, Rejeski J, Lang W, et al. Impact of a weight management program on health-related quality of life in overweight adults with type 2 diabetes. Arch Intern Med. 2009;169(2):163-171.

39. Foy CG, Lewis CE, Hairston KG, et al. Intensive lifestyle intervention improves physical function among obese adults with knee pain: findings from the Look AHEAD trial. Obesity (Silver Spring). 2011;19(1):83-93.

40. Rejeski WJ, Ip EH, Bertoni AG, et al. Lifestyle change and mobility in obese adults with type 2 diabetes. N Engl J Med. 2012;366(13):1209-1217.

41. Ikramuddin S, Korner J, Lee WJ, et al. Roux-en-Y gastric bypass vs intensive medical management for the control of type 2 diabetes, hypertension, and hyperlipidemia: the Diabetes Surgery Study randomized clinical trial. JAMA. 2013;309(21):2240-2249.

42. Schauer PR, Kashyap SR, Wolski K, et al. Bariatric surgery versus intensive medical therapy in obese patients with diabetes. $N$ Engl $J$ Med. 2012;366(17):1567-1576.

43. Mingrone G, Panunzi S, De Gaetano A, et al. Bariatric surgery versus conventional medical therapy for type 2 diabetes. $N$ Engl J Med. 2012;366(17):1577-1585.

44. Dorman RB, Serrot FJ, Miller CJ, et al. Case-matched outcomes in bariatric surgery for treatment of type 2 diabetes in the morbidly obese patient. Ann Surg. 2012;255(2):287-293.

45. Buchwald H, Estok R, Fahrbach K, et al. Weight and type 2 diabetes after bariatric surgery: systematic review and meta-analysis. Am J Med. 2009;122(3):248-256. e245.

46. Dixon JB, O'Brien PE, Playfair J, et al. Adjustable gastric banding and conventional therapy for type 2 diabetes: a randomized controlled trial. JAMA. 2008;299(3):316-323.

47. Cohen RV, Pinheiro JC, Schiavon CA, Salles JE, Wajchenberg BL, Cummings DE. Effects of gastric bypass surgery in patients with type 2 diabetes and only mild obesity. Diabetes Care. 2012;35(7):1420-1428. 
48. Mingrone G, Castagneto-Gissey L. Type 2 diabetes mellitus in 2013: a central role of the gut in glucose homeostasis. Nat Rev Endocrinol. 2014;10(2):73-74.

49. Sjöström L, Peltonen M, Jacobson P, et al. Bariatric surgery and longterm cardiovascular events. JAMA. 2012;307(1):56-65.

50. Sjöström L, Narbro K, Sjöström CD, et al. Effects of bariatric surgery on mortality in Swedish obese subjects. N Engl J Med. 2007;357(8): $741-752$.

51. Stewart KJ. Exercise training and the cardiovascular consequences of type 2 diabetes and hypertension: plausible mechanisms for improving cardiovascular health. JAMA. 2002;288(13):1622-1631.

52. Sluik D, Buijsse B, Muckelbauer R, et al. Physical activity and mortality in individuals with diabetes mellitus: a prospective study and metaanalysis. Arch Intern Med. 2012;172(17):1285-1295.

53. Ford ES, DeStefano F. Risk factors for mortality from all causes and from coronary heart disease among persons with diabetes. Findings from the National Health and Nutrition Examination Survey I Epidemiologic Follow-up Study. Am J Epidemiol. 1991;133(12):1220-1230.

54. Morrish NJ, Stevens LK, Fuller JH, Jarrett RJ, Keen H. Risk factors for macrovascular disease in diabetes mellitus: the London follow-up to the WHO Multinational Study of Vascular Disease in Diabetics. Diabetologia. 1991;34(8):590-594.

55. Turner RC, Millns H, Neil HA, et al. Risk factors for coronary artery disease in non-insulin dependent diabetes mellitus: United Kingdom Prospective Diabetes Study (UKPDS: 23). BMJ. 1998;316(7134):823-828.

56. Al-Delaimy WK, Manson JE, Solomon CG, et al. Smoking and risk of coronary heart disease among women with type 2 diabetes mellitus. Arch Intern Med. 2002;162(3):273-279.

57. Al-Delaimy WK, Willett WC, Manson JE, Speizer FE, Hu FB. Smoking and mortality among women with type 2 diabetes: the Nurses' Health Study cohort. Diabetes Care. 2001;24(12):2043-2048.

58. Qin R, Chen T, Lou Q, Yu D. Excess risk of mortality and cardiovascular events associated with smoking among patients with diabetes: meta-analysis of observational prospective studies. Int J Cardiol. 2013;167(2):342-350.

59. Nilsson PM, Cederholm J, Eeg-Olofsson K, et al. Smoking as an independent risk factor for myocardial infarction or stroke in type 2 diabetes: a report from the Swedish National Diabetes Register. Eur J Cardiovasc Prev Rehabil. 2009;16(4):506-512.

60. Neaton JD, Wentworth D. Serum cholesterol, blood pressure, cigarette smoking, and death from coronary heart disease. Overall findings and differences by age for 316,099 white men. Multiple Risk Factor Intervention Trial Research Group. Arch Intern Med. 1992;152(1):56-64.

61. Clair C, Rigotti NA, Porneala B, et al. Association of smoking cessation and weight change with cardiovascular disease among adults with and without diabetes. JAMA. 2013;309(10):1014-1021.

62. Bornfeldt KE, Tabas I. Insulin resistance, hyperglycemia, and atherosclerosis. Cell Metab. 2011;14(5):575-585.

63. Skyler JS, Bergenstal R, Bonow RO, et al. Intensive glycemic control and the prevention of cardiovascular events: implications of the ACCORD, ADVANCE, and VA diabetes trials: a position statement of the American Diabetes Association and a scientific statement of the American College of Cardiology Foundation and the American Heart Association. Circulation. 2009;119(2):351-357.

64. Diabetes Control and Complications Trial Research Group. The effect of intensive treatment of diabetes on the development and progression of long-term complications in insulin-dependent diabetes mellitus. N Engl J Med. 1993;329(14):977-986.

65. Nathan DM, Cleary PA, Backlund JY, et al. Intensive diabetes treatment and cardiovascular disease in patients with type 1 diabetes. $N$ Engl $J$ Med. 2005;353(25):2643-2653.

66. Genuth SM, Backlund JY, Bayless M, et al. Effects of prior intensive versus conventional therapy and history of glycemia on cardiac function in type 1 diabetes in the DCCT/EDIC. Diabetes. 2013;62(10):3561-3569.

67. UK Prospective Diabetes Study (UKPDS) Group. Intensive bloodglucose control with sulphonylureas or insulin compared with conventional treatment and risk of complications in patients with type 2 diabetes (UKPDS 33). Lancet. 1998;352(9131):837-853.
68. Holman RR, Paul SK, Bethel MA, Matthews DR, Neil HA. 10-Year follow-up of intensive glucose control in type 2 diabetes. $N$ Engl J Med. 2008;359(15):1577-1589.

69. Patel A, MacMahon S, Chalmers J, et al. Intensive blood glucose control and vascular outcomes in patients with type 2 diabetes. $N$ Engl J Med. 2008;358(24):2560-2572.

70. Duckworth W, Abraira C, Moritz T, et al. Glucose control and vascular complications in veterans with type 2 diabetes. $N$ Engl J Med. 2009;360(2):129-139.

71. Gerstein HC, Miller ME, Byington RP, et al. Effects of intensive glucose lowering in type 2 diabetes. $N$ Engl J Med. 2008;358(24):2545-2559.

72. Nissen SE, Wolski K. Effect of rosiglitazone on the risk of myocardial infarction and death from cardiovascular causes. $N$ Engl J Med. 2007;356(24):2457-2471

73. Riddle MC. More reasons to say goodbye to glyburide. J Clin Endocrinol Metab. 2010;95(11):4867-4870.

74. Home PD, Pocock SJ, Beck-Nielsen H, et al. Rosiglitazone evaluated for cardiovascular outcomes in oral agent combination therapy for type 2 diabetes (RECORD): a multicentre, randomised, open-label trial. Lancet. 2009;373(9681):2125-2135.

75. Mahaffey KW, Hafley G, Dickerson S, et al. Results of a reevaluation of cardiovascular outcomes in the RECORD trial. Am Heart J. 2013;166(2):240-249. e1.

76. US Food and Drug Administration. Guidance for industry: diabetes mellitus - evaluating cardiovascular risk in new antidiabetic therapies to treat type 2 diabetes. 2008. Available from: http://www.fda.gov/ downloads/Drugs/GuidanceComplianceRegulatoryInformation/ Guidances/ucm071627.pdf. Accessed January 8, 2014.

77. Ussher JR, Drucker DJ. Cardiovascular biology of the incretin system. Endocr Rev. 2012;33(2):187-215.

78. Green JB. The dipeptidyl peptidase- 4 inhibitors in type 2 diabetes mellitus: cardiovascular safety. Postgrad Med. 2012;124(4):54-61.

79. Lorber D. GLP-1 receptor agonists: effects on cardiovascular risk reduction. Cardiovasc Ther. 2013;31(4):238-249.

80. White WB, Cannon CP, Heller SR, et al. Alogliptin after acute coronary syndrome in patients with type 2 diabetes. NEngl J Med. 2013;369(14): 1327-1335.

81. Scirica BM, Bhatt DL, Braunwald E, et al. Saxagliptin and cardiovascular outcomes in patients with type 2 diabetes mellitus. N Engl J Med. 2013;369(14):1317-1326.

82. Riser Taylor S, Harris KB. The clinical efficacy and safety of sodium glucose cotransporter- 2 inhibitors in adults with type 2 diabetes mellitus. Pharmacotherapy. 2013;33(9):984-999.

83. Neal B, Perkovic V, de Zeeuw D, et al. Rationale, design, and baseline characteristics of the Canagliflozin Cardiovascular Assessment Study (CANVAS) - a randomized placebo-controlled trial. Am Heart J. 2013;166(2):217-223. e11.

84. Rosenstock J, Marx N, Kahn SE, et al. Cardiovascular outcome trials in type 2 diabetes and the sulphonylurea controversy: rationale for the activecomparator CAROLINA trial. Diab Vasc Dis Res. 2013;10(4):289-301.

85. Marso SP, Poulter NR, Nissen SE, et al. Design of the liraglutide effect and action in diabetes: evaluation of cardiovascular outcome results (LEADER) trial. Am Heart J. 2013;166(5):823-830. e5.

86. Vaccaro O, Masulli M, Bonora E, et al. The TOSCA.IT trial: a study designed to evaluate the effect of pioglitazone versus sulfonylureas on cardiovascular disease in type 2 diabetes. Diabetes Care. 2012;35(12):e82.

87. Punthakee Z, Bosch J, Dagenais G, et al. Design, history and results of the Thiazolidinedione Intervention with vitamin D Evaluation (TIDE) randomised controlled trial. Diabetologia. 2012;55(1):36-45.

88. Lincoff AM, Tardif JC, Neal B, et al. Evaluation of the dual peroxisome proliferator-activated receptor alpha/gamma agonist aleglitazar to reduce cardiovascular events in patients with acute coronary syndrome and type 2 diabetes mellitus: rationale and design of the AleCardio trial. Am Heart J. 2013;166(3):429-434.

89. ORIGIN Trial Investigators, Gerstein HC, Bosch J, et al. Basal insulin and cardiovascular and other outcomes in dysglycemia. N Engl J Med. 2012;367(4):319-328. 
90. Chen G, McAlister FA, Walker RL, Hemmelgarn BR, Campbell NR. Cardiovascular outcomes in Framingham participants with diabetes: the importance of blood pressure. Hypertension. 2011;57(5):891-897.

91. Sarwar N, Gao P, Seshasai SR, et al. Diabetes mellitus, fasting blood glucose concentration, and risk of vascular disease: a collaborative meta-analysis of 102 prospective studies. Lancet. 2010;375(9733): 2215-2222.

92. Lewington S, Clarke R, Qizilbash N, Peto R, Collins R. Age-specific relevance of usual blood pressure to vascular mortality: a meta-analysis of individual data for one million adults in 61 prospective studies. Lancet. 2002;360(9349):1903-1913.

93. Curb JD, Pressel SL, Cutler JA, et al. Effect of diuretic-based antihypertensive treatment on cardiovascular disease risk in older diabetic patients with isolated systolic hypertension. Systolic Hypertension in the Elderly Program Cooperative Research Group. JAMA. 1996;276(23):1886-1892.

94. Tuomilehto J, Rastenyte D, Birkenhäger WH, et al. Effects of calcium-channel blockade in older patients with diabetes and systolic hypertension. Systolic Hypertension in Europe Trial Investigators. N Engl J Med. 1999;340(9):677-684

95. Patel A, MacMahon S, Chalmers J, et al. Effects of a fixed combination of perindopril and indapamide on macrovascular and microvascular outcomes in patients with type 2 diabetes mellitus (the ADVANCE trial): a randomised controlled trial. Lancet. 2007;370(9590): 829-840.

96. Hansson L, Zanchetti A, Carruthers SG, et al. Effects of intensive blood-pressure lowering and low-dose aspirin in patients with hypertension: principal results of the Hypertension Optimal Treatment (HOT) randomised trial. HOT Study Group. Lancet. 1998;351(9118): 1755-1762.

97. UK Prospective Diabetes Study Group. Tight blood pressure control and risk of macrovascular and microvascular complications in type 2 diabetes: UKPDS 38. UK Prospective Diabetes Study Group. BMJ. 1998;317(7160):703-713.

98. Schrier RW, Estacio RO, Esler A, Mehler P. Effects of aggressive blood pressure control in normotensive type 2 diabetic patients on albuminuria, retinopathy and strokes. Kidney Int. 2002;61(3):1086-1097.

99. Rutter MK, Nesto RW. Blood pressure, lipids and glucose in type 2 diabetes: how low should we go? Re-discovering personalized care. Eur Heart J. 2011;32(18):2247-2255.

100. Reboldi G, Gentile G, Angeli F, Ambrosio G, Mancia G, Verdecchia P. Effects of intensive blood pressure reduction on myocardial infarction and stroke in diabetes: a meta-analysis in 73,913 patients. J Hypertens. 2011;29(7):1253-1269.

101. Arguedas JA, Perez MI, Wright JM. Treatment blood pressure targets for hypertension. Cochrane Database Syst Rev. 2009;(3):CD004349.

102. Cooper-DeHoff RM, Gong Y, Handberg EM, et al. Tight blood pressure control and cardiovascular outcomes among hypertensive patients with diabetes and coronary artery disease. JAMA. 2010;304(1):61-68.

103. Bangalore S, Kumar S, Lobach I, Messerli FH. Blood pressure targets in subjects with type 2 diabetes mellitus/impaired fasting glucose: observations from traditional and Bayesian random-effects meta-analyses of randomized trials. Circulation. 2011;123(24): 2799-2810.

104. Sleight P, Redon J, Verdecchia P, et al. Prognostic value of blood pressure in patients with high vascular risk in the Ongoing Telmisartan Alone and in combination with Ramipril Global Endpoint Trial study. J Hypertens. 2009;27(7):1360-1369.

105. Redon J, Mancia G, Sleight P, et al. Safety and efficacy of low blood pressures among patients with diabetes: subgroup analyses from the ONTARGET (ONgoing Telmisartan Alone and in combination with Ramipril Global Endpoint Trial). J Am Coll Cardiol. 2012;59(1): 74-83.

106. Mancia G, Fagard R, Narkiewicz K, et al. 2013 ESH/ESC Guidelines for the management of arterial hypertension: the Task Force for the management of arterial hypertension of the European Society of Hypertension (ESH) and of the European Society of Cardiology (ESC). J Hypertens. 2013;31(7):1281-1357.
107. International Diabetes Federation. Global Guideline for Type 2 Diabetes. Brussels: IDF; 2012.

108. Chobanian AV, Bakris GL, Black HR, et al. Seventh Report of the Joint National Committee on Prevention, Detection, Evaluation, and Treatment of High Blood Pressure. Hypertension. 2003;42(6): $1206-1252$.

109. ALLHAT Officers and Coordinators for the ALLHAT Collaborative Research Group. Major outcomes in high-risk hypertensive patients randomized to angiotensin-converting enzyme inhibitor or calcium channel blocker vs diuretic: the Antihypertensive and Lipid-Lowering Treatment to Prevent Heart Attack Trial (ALLHAT). JAMA. 2002;288(23):2981-2997.

110. Tatti P, Pahor M, Byington RP, et al. Outcome results of the Fosinopril Versus Amlodipine Cardiovascular Events Randomized Trial (FACET) in patients with hypertension and NIDDM. Diabetes Care. 1998;21(4):597-603.

111. Estacio RO, Jeffers BW, Hiatt WR, Biggerstaff SL, Gifford N, Schrier RW. The effect of nisoldipine as compared with enalapril on cardiovascular outcomes in patients with non-insulin-dependent diabetes and hypertension. N Engl J Med. 1998;338(10):645-652.

112. Lindholm LH, Hansson L, Ekbom T, et al. Comparison of antihypertensive treatments in preventing cardiovascular events in elderly diabetic patients: results from the Swedish Trial in Old Patients with Hypertension-2. STOP Hypertension-2 Study Group. J Hypertens. 2000;18(11):1671-1675.

113. Niskanen L, Hedner T, Hansson L, Lanke J, Niklason A. Reduced cardiovascular morbidity and mortality in hypertensive diabetic patients on first-line therapy with an ACE inhibitor compared with a diuretic/ beta-blocker-based treatment regimen: a subanalysis of the Captopril Prevention Project. Diabetes Care. 2001;24(12):2091-2096.

114. Lindholm LH, Ibsen H, Dahlöf B, et al. Cardiovascular morbidity and mortality in patients with diabetes in the Losartan Intervention For Endpoint reduction in hypertension study (LIFE): a randomised trial against atenolol. Lancet. 2002;359(9311):1004-1010.

115. McMurray JJ, Ostergren J, Swedberg K, et al. Effects of candesartan in patients with chronic heart failure and reduced left-ventricular systolic function taking angiotensin-converting-enzyme inhibitors: the CHARM-Added trial. Lancet. 2003;362(9386):767-771.

116. Pfeffer MA, Swedberg K, Granger CB, et al. Effects of candesartan on mortality and morbidity in patients with chronic heart failure: the CHARM-Overall programme. Lancet. 2003;362(9386):759-766.

117. Granger CB, McMurray JJ, Yusuf S, et al. Effects of candesartan in patients with chronic heart failure and reduced left-ventricular systolic function intolerant to angiotensin-converting-enzyme inhibitors: the CHARM-Alternative trial. Lancet. 2003;362(9386):772-776.

118. Schrier RW, Estacio RO, Mehler PS, Hiatt WR. Appropriate blood pressure control in hypertensive and normotensive type 2 diabetes mellitus: a summary of the ABCD trial. Nat Clin Pract Nephrol. 2007;3(8):428-438.

119. ONTARGET Investigators. Telmisartan, ramipril, or both in patients at high risk for vascular events. $N$ Engl J Med. 2008;358(15): $1547-1559$

120. Jamerson K, Weber MA, Bakris GL, et al. Benazepril plus amlodipine or hydrochlorothiazide for hypertension in high-risk patients. $N$ Engl J Med. 2008;359(23):2417-2428.

121. Aksnes TA, Skårn SN, Kjeldsen SE. Treatment of hypertension in diabetes: what is the best therapeutic option? Expert Rev Cardiovasc Ther. 2012;10(6):727-734.

122. Reboldi G, Gentile G, Angeli F, Verdecchia P. Optimal therapy in hypertensive subjects with diabetes mellitus. Curr Atheroscler Rep. 2011;13(2):176-185

123. Turnbull F, Neal B, Algert C, et al. Effects of different blood pressurelowering regimens on major cardiovascular events in individuals with and without diabetes mellitus: results of prospectively designed overviews of randomized trials. Arch Intern Med. 2005;165(12):1410-1419.

124. Krentz AJ. Lipoprotein abnormalities and their consequences for patients with type 2 diabetes. Diabetes Obes Metab. 2003;5 Suppl 1: S19-S27. 
125. Mooradian AD. Dyslipidemia in type 2 diabetes mellitus. Nat Clin Pract Endocrinol Metab. 2009;5(3):150-159.

126. Colhoun HM, Betteridge DJ, Durrington PN, et al. Primary prevention of cardiovascular disease with atorvastatin in type 2 diabetes in the Collaborative Atorvastatin Diabetes Study (CARDS): multicentre randomised placebo-controlled trial. Lancet. 2004;364(9435):685-696.

127. Collins R, Armitage J, Parish S, Sleigh P, Peto R. MRC/BHF Heart Protection Study of cholesterol-lowering with simvastatin in 5963 people with diabetes: a randomised placebo-controlled trial. Lancet. 2003;361(9374):2005-2016.

128. Goldberg RB, Mellies MJ, Sacks FM, et al. Cardiovascular events and their reduction with pravastatin in diabetic and glucose-intolerant myocardial infarction survivors with average cholesterol levels: subgroup analyses in the cholesterol and recurrent events (CARE) trial. The Care Investigators. Circulation. 1998;98(23):2513-2519.

129. Kearney PM, Blackwell L, Collins R, et al. Efficacy of cholesterollowering therapy in 18,686 people with diabetes in 14 randomised trials of statins: a meta-analysis. Lancet. 2008;371(9607):117-125.

130. Pyorala K, Pedersen TR, Kjekshus J, Faergeman O, Olsson AG, Thorgeirsson G. Cholesterol lowering with simvastatin improves prognosis of diabetic patients with coronary heart disease. A subgroup analysis of the Scandinavian Simvastatin Survival Study (4S). Diabetes Care. 1997;20(4):614-620.

131. Sever PS, Poulter NR, Dahlöf B, et al. Reduction in cardiovascular events with atorvastatin in 2,532 patients with type 2 diabetes: AngloScandinavian Cardiac Outcomes Trial - lipid-lowering arm (ASCOTLLA). Diabetes Care. 2005;28(5):1151-1157.

132. Shepherd J, Barter P, Carmena R, et al. Effect of lowering LDL cholesterol substantially below currently recommended levels in patients with coronary heart disease and diabetes: the Treating to New Targets (TNT) study. Diabetes Care. 2006;29(6):1220-1226.

133. Briel M, Ferreira-Gonzalez I, You JJ, et al. Association between change in high density lipoprotein cholesterol and cardiovascular disease morbidity and mortality: systematic review and meta-regression analysis. BMJ. 2009;338:b92.

134. Singh IM, Shishehbor MH, Ansell BJ. High-density lipoprotein as a therapeutic target: a systematic review. JAMA. 2007;298(7):786-798.

135. ACCORD Study Group. Effects of combination lipid therapy in type 2 diabetes mellitus. N Engl J Med. 2010;362(17):1563-1574.

136. Aim-High Investigators. Niacin in patients with low HDL cholesterol levels receiving intensive statin therapy. $N$ Engl J Med. 2011;365(24): 2255-2267.

137. Schwartz GG, Olsson AG, Abt M, et al. Effects of dalcetrapib in patients with a recent acute coronary syndrome. $N$ Engl $J$ Med. 2012;367(22):2089-2099.

138. Miller M, Stone NJ, Ballantyne C, et al. Triglycerides and cardiovascular disease: a scientific statement from the American Heart Association. Circulation. 2011;123(20):2292-2333.

139. Grundy SM, Cleeman JI, Merz CN, et al. Implications of recent clinical trials for the National Cholesterol Education Program Adult Treatment Panel III guidelines. Circulation. 2004;110(2):227-239.

140. Wong ND, Patao C, Wong K, Malik S, Franklin SS, Iloeje U. Trends in control of cardiovascular risk factors among US adults with type 2 diabetes from 1999 to 2010: comparison by prevalent cardiovascular disease status. Diab Vasc Dis Res. 2013;10(6):505-513.

141. Ford ES. Trends in the control of risk factors for cardiovascular disease among adults with diagnosed diabetes: findings from the National Health and Nutrition Examination Survey 1999-2008. J Diabetes. 2011;3(4):337-347.

142. Alzahrani SH, Ajjan RA. Coagulation and fibrinolysis in diabetes. Diab Vasc Dis Res. 2010;7(4):260-273.

143. Ferreiro JL, Gómez-Hospital JA, Angiolillo DJ. Platelet abnormalities in diabetes mellitus. Diab Vasc Dis Res. 2010;7(4):251-259.

144. Antiplatelet Trialists' Collaboration. Collaborative overview of randomised trials of antiplatelet therapy - I: Prevention of death, myocardial infarction, and stroke by prolonged antiplatelet therapy in various categories of patients. $B M J .1994 ; 308(6921): 81-106$.
145. Antithrombotic Trialists Collaboration. Collaborative meta-analysis of randomised trials of antiplatelet therapy for prevention of death, myocardial infarction, and stroke in high risk patients. $B M J$. 2002;324(7329):71-86.

146. ETDRS Investigators. Aspirin effects on mortality and morbidity in patients with diabetes mellitus. Early Treatment Diabetic Retinopathy Study report 14. JAMA. 1992;268(10):1292-1300.

147. Belch J, MacCuish A, Campbell I, et al. The prevention of progression of arterial disease and diabetes (POPADAD) trial: factorial randomised placebo controlled trial of aspirin and antioxidants in patients with diabetes and asymptomatic peripheral arterial disease. BMJ. 2008;337:a1840

148. Ogawa H, Nakayama M, Morimoto T, et al. Low-dose aspirin for primary prevention of atherosclerotic events in patients with type 2 diabetes: a randomized controlled trial. JAMA. 2008;300(18):2134-2141.

149. Pignone M, Alberts MJ, Colwell JA, et al. Aspirin for primary prevention of cardiovascular events in people with diabetes: a position statement of the American Diabetes Association, a scientific statement of the American Heart Association, and an expert consensus document of the American College of Cardiology Foundation. Diabetes Care. 2010;33(6):1395-1402.

150. Baigent C, Blackwell L, Collins R, et al. Aspirin in the primary and secondary prevention of vascular disease: collaborative metaanalysis of individual participant data from randomised trials. Lancet. 2009;373(9678):1849-1860.

151. De Berardis G, Sacco M, Strippoli GF, et al. Aspirin for primary prevention of cardiovascular events in people with diabetes: metaanalysis of randomised controlled trials. BMJ. 2009;339:b4531.

152. Zhang C, Sun A, Zhang P, et al. Aspirin for primary prevention of cardiovascular events in patients with diabetes: a meta-analysis. Diabetes Res Clin Pract. 2010;87(2):211-218.

153. Calvin AD, Aggarwal NR, Murad MH, et al. Aspirin for the primary prevention of cardiovascular events: a systematic review and metaanalysis comparing patients with and without diabetes. Diabetes Care. 2009;32(12):2300-2306.

154. Butalia S, Leung AA, Ghali WA, Rabi DM. Aspirin effect on the incidence of major adverse cardiovascular events in patients with diabetes mellitus: a systematic review and meta-analysis. Cardiovasc Diabetol. 2011;10:25.

155. De Berardis G, Sacco M, Evangelista V, et al. Aspirin and Simvastatin Combination for Cardiovascular Events Prevention Trial in Diabetes (ACCEPT-D): design of a randomized study of the efficacy of lowdose aspirin in the prevention of cardiovascular events in subjects with diabetes mellitus treated with statins. Trials. 2007;8:21.

156. Bhatt DL, Marso SP, Hirsch AT, Ringleb PA, Hacke W, Topol EJ. Amplified benefit of clopidogrel versus aspirin in patients with diabetes mellitus. Am J Cardiol. 2002;90(6):625-628.

157. Patrono C, Andreotti F, Arnesen H, et al. Antiplatelet agents for the treatment and prevention of atherothrombosis. Eur Heart $J$. 2011;32(23):2922-2932.

158. Hall HM, Banerjee S, McGuire DK. Variability of clopidogrel response in patients with type 2 diabetes mellitus. Diab Vasc Dis Res. 2011;8(4):245-253.

159. Wiviott SD, Braunwald E, McCabe $\mathrm{CH}$, et al. Prasugrel versus clopidogrel in patients with acute coronary syndromes. $N$ Engl $\mathrm{J} M e d$. 2007;357(20):2001-2015.

160. Wiviott SD, Braunwald E, Angiolillo DJ, et al. Greater clinical benefit of more intensive oral antiplatelet therapy with prasugrel in patients with diabetes mellitus in the trial to assess improvement in therapeutic outcomes by optimizing platelet inhibition with prasugrel-Thrombolysis in Myocardial Infarction 38. Circulation. 2008;118(16):1626-1636.

161. Roe MT, Armstrong PW, Fox KA, et al. Prasugrel versus clopidogrel for acute coronary syndromes without revascularization. NEngl J Med. 2012;367(14):1297-1309.

162. Wallentin L, Becker RC, Budaj A, et al. Ticagrelor versus clopidogrel in patients with acute coronary syndromes. $N$ Engl J Med. 2009;361(11): 1045-1057. 
163. James S, Angiolillo DJ, Cornel JH, et al. Ticagrelor vs clopidogrel in patients with acute coronary syndromes and diabetes: a substudy from the PLATelet inhibition and patient Outcomes (PLATO) trial. Eur Heart J. 2010;31(24):3006-3016.

164. Alexopoulos D, Xanthopoulou I, Mavronasiou E, et al. Randomized assessment of ticagrelor versus prasugrel antiplatelet effects in patients with diabetes. Diabetes Care. 2013;36(8):2211-2216.

165. Daiichi Sankyo, Eli Lilly. Effient (prasugrel) tablets [package insert]. 2009. Available from: http://www.accessdata.fda.gov/ drugsatfda_docs/label/2010/022307s0021bl.pdf. Accessed January 8, 2014.

166. AstraZeneca. Brilinta ${ }^{\circledR}$ (ticagrelor) tablets [package insert]. 2012. Available from: http://www.accessdata.fda.gov/drugsatfda_docs/ label/2013/022433s0081bl.pdf. Accessed January 8, 2014.
167. Gaede P, Vedel P, Larsen N, Jensen GV, Parving HH, Pedersen O. Multifactorial intervention and cardiovascular disease in patients with type 2 diabetes. $N$ Engl J Med. 2003;348(5):383-393.

168. Gaede P, Pedersen O. Intensive integrated therapy of type 2 diabetes: implications for long-term prognosis. Diabetes. 2004;53 Suppl 3: S39-S47.

169. Gaede P, Lund-Andersen H, Parving HH, Pedersen O. Effect of a multifactorial intervention on mortality in type 2 diabetes. $N$ Engl J Med. 2008;358(6):580-591.

170. Vaccaro O, Franzini L, Miccoli R, et al. Feasibility and effectiveness in clinical practice of a multifactorial intervention for the reduction of cardiovascular risk in patients with type 2 diabetes: the 2-year interim analysis of the MIND.IT study: a cluster randomized trial. Diabetes Care. 2013;36(9):2566-2572.

\section{Publish your work in this journal}

Diabetes, Metabolic Syndrome and Obesity: Targets and Therapy is an international, peer-reviewed open-access journal committed to the rapid publication of the latest laboratory and clinical findings in the fields of diabetes, metabolic syndrome and obesity research. Original research, review, case reports, hypothesis formation, expert opinion and commentaries are all considered for publication. The manuscript management system is completely online and includes a very quick and fair peer-review system, which is all easy to use. Visit http://www.dovepress.com/testimonials.php to read real quotes from published authors.

Submit your manuscript here: http://www.dovepress.com/diabetes-metabolic-syndrome-and-obesity-targets-and-therapy-journal 